\title{
Prevalence of Behavioral Health Problems Among Adults With and Without Communication Disabilities
}

\author{
Michelle L. Stransky, PhD, Jennifer Y. Oshita, MS, CCC-SLP, and \\ Megan A. Morris, PhD, MPH, CCC-SLP
}

Background: Adults with communication disabilities (CDs) experience poor health and health care outcomes. Few studies have examined behavioral health outcomes among this population. We compare the behavioral health of adults with CDs to their peers without such disabilities.

Methods: Retrospective cohort study examining the 2012 National Health Interview Survey Voice, Speech, and Language Supplement. We compared adults $(>17$ years old) with voice only $(n=2169)$, speech/language $(S L)$ only $(n=730)$, and speech/language and voice $(S L V ; n=450)$ disabilities to

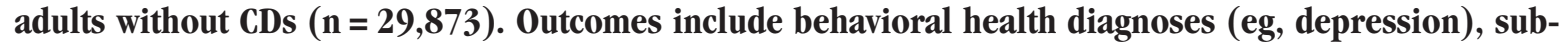
stance misuse (eg, excessive alcohol or tobacco use), experiences (eg, nonspecific psychological distress), and health care utilization. Unadjusted Pearson's $\chi^{2}$ and adjusted logistic regression analyses controlling for sociodemographic, health, and other disability measures were conducted.

Results: Adults with CDs more frequently reported diagnoses $(7.1 \%$ to $35.9 \%$ vs $1.8 \%$ to $8.6 \%)$, substance misuse (SL only: $15.5 \%$ vs 5.5\%), and nonspecific psychological distress (SL only: 14.7\%; SLV: $22.3 \%$ vs $2.3 \%$ ) compared with adults without CDs (all $P<.001)$. These findings were consistent for all outcomes and in multivariate analyses. Odds ratios ranged from $1.4(99.7 \% \mathrm{CI}, 1.1-1.7)$ to $5.0(99.7 \%$ CI, 3.6-6.8). Adults with CDs more frequently endorsed visiting mental health professionals compared with adults without CDs (voice only: $11.4 \%$; SL only: $19.1 \%$; SLV: $23.1 \%$; vs $6.8 \%$, all $P<.001$ ), but these differences became nonsignificant in multivariate analyses.

Conclusions: Adults with CDs experience poorer behavioral health and health care outcomes compared with persons without CDs. Barriers to identification and treatment related to CDs must be addressed for persons with CDs. (J Am Board Fam Med 2020;33:932-941.)

Keywords: Communication Disorders, Logistic Models, Mental Health, Multivariate Analysis, Outcomes Assessment, Psychological Distress, Retrospective Studies, Speech, Substance-Related Disorders, Surveys and Questionnaires

\section{Introduction}

Adults with communication disabilities (CDs) experience poorer health and health care outcomes ${ }^{1,2}$ and increased restrictions in social participation

This article was externally peer reviewed.

Submitted 12 May 2020; revised 9 July 2020; accepted 9 July 2020.

From the Department of General Academic Pediatrics, Boston Medical Center, Boston, MA (MLS); Clinical and Translational Sciences Program, University of Vermont, Burlington (JYO); Rehabilitation Therapies Department, University of Vermont Medical Center, Burlington (JYO); Adult and Child Consortium for Health Outcomes Research and Delivery Science, Children's Hospital Colorado, University of Colorado Anschutz Medical Campus, Aurora (MAM).

Funding: This project was funded under Grant Number T32HS022242 from the Agency for Healthcare Research and Quality (AHRQ), U.S. Department of Health and Human Services, to MLS. The authors are solely responsible for this document's contents, findings, and conclusions, which do not necessarily represent the views of AHRQ. compared with their nondisabled peers. ${ }^{3,4}$ Defined as impairments in producing and/or understanding verbal or written language, CDs affect approximately $10 \%$ of adults in the United States, although only $2 \%$ report being formally diagnosed. ${ }^{5}$ CDs can stem from a variety of disease etiologies, including voice disabilities related to head and neck cancer, speech sound disabilities from Parkinson's Disease, or the language disability of aphasia following a stroke. In

Readers should not interpret any statement in this product as an official position of AHRQ or of the U.S. Department of Health and Human Services. None of the authors has any affiliation or financial involvement that conflicts with the material presented in this product.

Conflict of interest: None.

Corresponding author: Michelle L. Stransky, PhD, Department of General Academic Pediatrics, Boston Medical Center, 801 Albany St. Boston, MA 02119 (E-mail: michelle.stransky@bmc.org). 
addition to worse health outcomes and restricted social participation, persons with CDs seem similar to persons with other disabilities, who have lower incomes, fewer years of education, and higher rates of unemployment compared with their peers without CDs. ${ }^{2,6}$

Behavioral health disorders, defined as "mental health and substance abuse conditions, stress-linked physical symptoms, patient activation and health behaviors," are among the conditions with the highest disease burdens in the United States. ${ }^{8}$ Existing literature addressing behavioral health outcomes among persons with CDs has traditionally been oriented by disease,, 10 resulting in a fragmented and siloed understanding of the shared experience of CD across diverse conditions. Among these isolated CD subgroups, scholarship suggests a pattern of poorer behavioral health outcomes. For example, 1 in every 5 adults who have had a laryngectomy surgery were diagnosed with psychiatric disorders within 2 decades following their surgery. ${ }^{11}$ Persons with common voice disabilities like muscle tension dysphonia or vocal-fold lesions report elevated stress, anxiety, and depression compared with those without these disorders at rates of between $25 \%$ to $37 \% .^{12,13}$ In contrast, the prevalence of any mental illness (including mental, behavioral, or emotional disorder) in the US population is $18.9 \% .{ }^{14}$ Adults who stutter have a significantly higher prevalence of smoking, drug use, and depressive symptoms than nonstuttering adults. ${ }^{15}$ Finally, aphasia is 1 of the top 3 predictors of depression after experiencing a stroke ${ }^{16}$ and is associated with severe and persistent mood disorder. ${ }^{17}$

The US federal prevention agenda, Healthy People 2020, identified the health of individuals with disabilities as a priority area. ${ }^{18} \mathrm{We}$ contribute to this scholarship by examining the experiences of mental health and substance misuse, as well as access to behavioral health care, comparing adults with and without CDs. To do so, we leveraged the Voice, Speech and Language supplement of the 2012 National Health Interview Survey (NHIS).

\section{Methods \\ Data and Sample}

We conducted a retrospective cohort study, examining data from the 2012 NHIS. ${ }^{19}$ The NHIS is a nationally representative survey administered annually by the US Census Bureau. US households are selected using a multi-stage sampling technique. Information on health behaviors, conditions, and health care experiences are collected on all civilian household members. One adult from each family is randomly selected for more extensive data collection. In 2012, the NHIS Sample Adult questionnaire, which contained supplementary questions on $\mathrm{CD}$, gathered information on 34,525 adults ( $>17$ years old; $61.2 \%$ response rate). Complete information on $\mathrm{CD}$ and behavioral health questions were available for 33,222 adults (96.2\% of the sample). The Institutional Review Board determined this study was exempt from review because the NHIS is publicly available.

We created a mutually exclusive measure to categorize persons without $C D(n=29,873)$, with voice only disabilities ( $\mathrm{n}=2169)$, with speech and/or language (SL) only disabilities $(\mathrm{n}=730)$, and with speech and/or language and voice (SLV) disabilities $(n=450)$ based on responses to questions about voice, speech, and language problems in the past 12 months (Table 1). Voice only and SL only disabilities were categorized separately because of differences in the duration of such problems (on average, voice disabilities past 56 days per year compared with 142 and 195 days for respondents with speech or language disabilities). ${ }^{5}$ An SLV group was created to capture the impact of co-occurring CDs. CDs resulting from primary sensory impairments (hearing and visual) were not included in this analysis as data on these populations are more

\section{Table 1. Communication Disabilities Definitions}

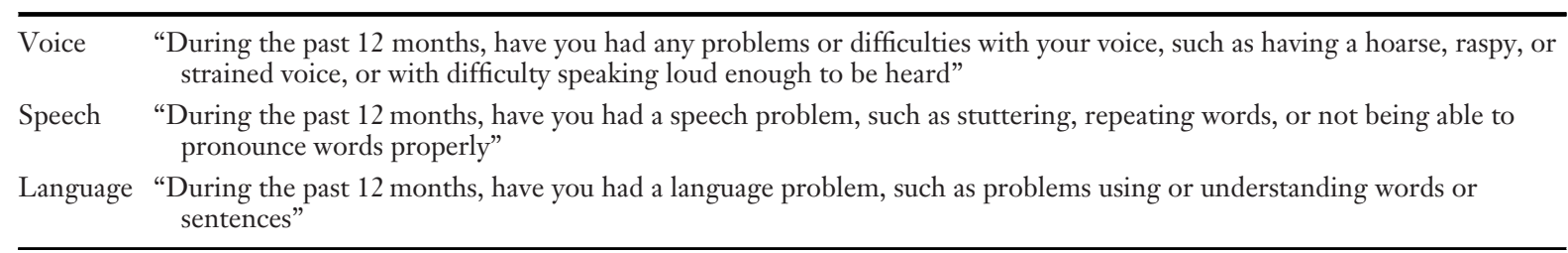

Questions from the 2012 National Health Interview Survey Sample Adult Questionnaire Supplement on Communication Disabilities. 
readily available and, thus, comparatively better studied.

\section{Outcomes}

\section{Diagnoses}

Adults were asked whether they had ever been diagnosed with attention deficit disorder/attention deficit hyperactivity disorder (ADD/ADHD) and bipolar disorder. Persons were asked whether they had been diagnosed with phobias, depression, or other mental health disorders during the past 12 months.

\section{Substance Use}

Adults were queried on excessive alcohol, tobacco, or other substance use during the past 12 months.

\section{Stress-Related Experiences}

Adults were asked whether they experienced fatigue or lack of energy for $>3$ days; excessive sleepiness during the day; insomnia or trouble sleeping; feeling anxious, nervous or worried; and feeling stressed during the last year. Respondents were categorized as experiencing difficulty "participat[ing] in social activities such as visiting friends, attending clubs and meetings, going to parties" if they endorsed having any difficulty (vs no difficulty). ${ }^{19}$

Nonspecific psychological distress was measured by the K-6 scale. ${ }^{20}$ These questions query experiences of being nervous, restless or fidgety, hopeless, worthless, and feeling that everything was an effort during the past 30 days on a 5 -point scale ranging from "All the Time" (1) to "None of the Time" (5). Responses were reverse coded from 0 to 4 and summed across items. Persons with a final score $>12$ were categorized as experiencing nonspecific psychological distress. Persons who reported experiencing at least 1 of these feelings all, most, or some of the time were asked how much "these feelings interfered with your life or activities." Persons who reported "a lot" of interference were categorized separately from those who reported lower levels of interference.

\section{Health care}

All respondents were asked whether they had visited a mental health professional and whether they forewent mental health care because they could not afford it in the past 12 months.

\section{Other Measures}

Self-reported age, sex, race/ethnicity, employment status, marital status, educational attainment, region of residence, and health insurance status were used as control measures. Poverty status was measured as family-size adjusted income in comparison to the federal poverty line. Cases with missing data were imputed by the National Center for Health Statistics. Persons who endorsed physical, cognitive, vision, independent living, or self-care limitations or being deaf or hard of hearing were coded as having any other disability. A summary measure of 0,1 , or $>1$ chronic conditions was created based on endorsement of hypertension, cardiovascular disease, stroke, emphysema or chronic obstructive pulmonary disease, asthma, cancer, diabetes, or arthritis.

\section{Analysis}

We analyzed the NHIS using Stata $15,{ }^{21}$ accounting for the Sample Adults weights and the complex sampling design. Statistical significance was set at 0.0029 to account for multiple outcomes. ${ }^{22} \mathrm{We}$ first examined unadjusted associations between behavioral health and CD using Pearson's $\chi^{2}$ test. Logistic regression analyses (odds ratios and $99.7 \% \mathrm{CIs}$ ) were used to assess these associations, controlling for sociodemographic, health, and other disability measures. Regression analyses of health care also controlled for behavioral health conditions and experiences.

\section{Results}

In our sample, a total of 3349 adults reported a CD. Adults with CDs more frequently reported other disabilities and multiple chronic conditions than their peers without CDs (Table 2). For example, approximately $25 \%$ of persons without CDs reported $>1$ chronic condition compared with $40 \%$ of persons with voice disabilities, $44 \%$ of persons with SL disabilities, and $62 \%$ of persons with SLV disabilities. Adults with CDs were more frequently unmarried, unemployed, relied on public insurance, and lived in families at or near the poverty line. Persons with SL only and SLV disabilities seemed to fare the worst compared with their peers without CDs.

Adults with CDs more frequently reported ever being diagnosed with ADHD/ADD (SL only: 14.2\% $P<.001$ ) and bipolar disorder (SL only: $11.7 \%$; SLV: $11.4 \%$; all $P<.001)$ compared with adults without CDs (3.8\% and $1.8 \%$, respectively; Table 3). Fewer than $9 \%$ of adults without CDs were currently 
Table 2. Characteristics of Persons with Communication Disabilities $(n=33,222)$

\begin{tabular}{|c|c|c|c|c|c|c|c|c|}
\hline & \multicolumn{2}{|c|}{$\begin{array}{c}\text { No Communication } \\
\text { Disability } \\
\end{array}$} & \multicolumn{2}{|c|}{$\begin{array}{l}\text { Voice Only } \\
\text { Disability } \\
\end{array}$} & \multicolumn{2}{|c|}{$\begin{array}{c}\text { Speech/Language } \\
\text { Only Disability }\end{array}$} & \multicolumn{2}{|c|}{$\begin{array}{c}\text { Speech/ } \\
\text { Language \& } \\
\text { Voice } \\
\text { Disability } \\
\end{array}$} \\
\hline & $\%$ & (n) & $\%$ & (n) & $\%$ & (n) & $\%$ & (n) \\
\hline Total & 90.2 & $(29,873)$ & 6.4 & $(2169)$ & 2.2 & $(730)$ & 1.2 & $(450)$ \\
\hline Any other disability & 14.7 & $(5076)$ & 24.1 & $(623)$ & 52.8 & $(426)$ & 64.0 & (318) \\
\hline \multicolumn{9}{|c|}{ Multiple chronic conditions } \\
\hline None & 50.2 & $(14,249)$ & 32.1 & $(603)$ & 31.7 & $(208)$ & 20.7 & $(77)$ \\
\hline One & 25.0 & $(7474)$ & 27.5 & $(582)$ & 24.4 & $(176)$ & 17.9 & (79) \\
\hline$>1$ & 24.9 & $(8150)$ & 40.4 & (984) & 43.9 & $(346)$ & 61.5 & (294) \\
\hline \multicolumn{9}{|l|}{ Race/ethnicity } \\
\hline Hispanic & 15.3 & $(5242)$ & 9.1 & $(230)$ & 15.0 & $(127)$ & 14.5 & $(71)$ \\
\hline White, non-Hispanic & 66.8 & $(17,907)$ & 76.7 & $(1537)$ & 65.9 & $(412)$ & 66.5 & (266) \\
\hline Black, non-Hispanic & 11.6 & $(4467)$ & 10.8 & $(313)$ & 14.4 & $(153)$ & 14.7 & (89) \\
\hline Other, Non-Hispanic & 6.2 & $(2257)$ & 3.4 & (89) & 4.7 & (38) & 4.3 & (24) \\
\hline Married & 54.1 & $(13,284)$ & 50.2 & $(862)$ & 36.1 & $(211)$ & 36.8 & (129) \\
\hline Employed & 62.2 & $(17,803)$ & 57.2 & $(1155)$ & 39.0 & $(277)$ & 37.2 & (144) \\
\hline \multicolumn{9}{|l|}{ Educational attainment } \\
\hline Less than high school & 13.7 & $(4658)$ & 11.7 & $(279)$ & 22.5 & (199) & 28.6 & (133) \\
\hline High school graduate & 26.2 & $(7739)$ & 22.9 & $(527)$ & 30.4 & $(207)$ & 30.8 & (132) \\
\hline Some college & 20.4 & $(5908)$ & 22.4 & $(478)$ & 21.6 & $(155)$ & 23.3 & (96) \\
\hline College degree & 39.7 & $(11,568)$ & 43.0 & $(885)$ & 25.4 & $(169)$ & 17.2 & (89) \\
\hline \multicolumn{9}{|l|}{ Poverty status* } \\
\hline$<100 \% \mathrm{FPL}$ & 13.4 & $(5003)$ & 12.9 & (374) & 25.0 & $(216)$ & 25.6 & (133) \\
\hline 100 to $199 \% \mathrm{FPL}$ & 19.0 & $(5425)$ & 19.2 & (404) & 25.7 & $(168)$ & 28.2 & (108) \\
\hline 200 to $399 \% \mathrm{FPL}$ & 29.8 & $(7546)$ & 30.7 & $(578)$ & 27.2 & $(163)$ & 30.0 & (106) \\
\hline$\geq 400 \% \mathrm{FPL}$ & 37.7 & $(8780)$ & 37.3 & $(608)$ & 22.1 & $(117)$ & 16.3 & (63) \\
\hline \multicolumn{9}{|l|}{ Health insurance } \\
\hline Uninsured & 17.0 & $(5419)$ & 12.7 & $(300)$ & 18.7 & (139) & 16.7 & (64) \\
\hline Public only & 16.4 & $(5852)$ & 17.6 & $(464)$ & 32.5 & $(276)$ & 39.0 & (200) \\
\hline Any private & 66.6 & $(18,602)$ & 69.7 & $(1405)$ & 48.9 & $(315)$ & 44.2 & (186) \\
\hline \multicolumn{9}{|l|}{ Region of residence } \\
\hline Northeast & 18.3 & $(5034)$ & 16.4 & $(337)$ & 16.4 & (99) & 11.9 & $(53)$ \\
\hline Midwest & 22.3 & $(6094)$ & 28.2 & $(556)$ & 24.3 & (154) & 23.0 & $(86)$ \\
\hline South & 36.5 & $(10,889)$ & 36.1 & $(759)$ & 37.1 & $(281)$ & 40.5 & (178) \\
\hline West & 22.9 & $(7856)$ & 19.3 & $(517)$ & 22.1 & (196) & 24.6 & (133) \\
\hline Female & 51.0 & $(16,461)$ & 66.3 & (1464) & 48.6 & $(370)$ & 48.5 & (244) \\
\hline \multicolumn{9}{|l|}{ Age, years } \\
\hline 18 to 24 & 12.7 & (2935) & 12.0 & $(217)$ & 20.8 & (95) & 17.4 & (48) \\
\hline 25 to 34 & 18.0 & $(5461)$ & 15.7 & (326) & 14.7 & (114) & 10.4 & (44) \\
\hline 35 to 44 & 17.3 & $(5106)$ & 14.3 & (306) & 13.2 & $(100)$ & 11.8 & $(52)$ \\
\hline 45 to 54 & 18.6 & $(5153)$ & 18.7 & $(350)$ & 16.9 & $(120)$ & 17.7 & $(80)$ \\
\hline 55 to 64 & 16.1 & $(5019)$ & 16.4 & $(385)$ & 17.3 & $(147)$ & 18.4 & (97) \\
\hline$\geq 65$ & 17.3 & (6199) & 22.9 & $(585)$ & 17.2 & (154) & 24.4 & (129) \\
\hline
\end{tabular}

FPL, federal poverty line.

Percentages may not sum to 100 due to rounding.

*Poverty status was imputed by the National Center for Health Statistics. The sample sizes shown are from the cases that were not imputed. 
Communication Disability

\begin{tabular}{|c|c|c|c|c|c|c|c|c|c|c|c|}
\hline & \multicolumn{2}{|c|}{$\begin{array}{l}\text { No communica- } \\
\text { tion Disability } \\
\end{array}$} & \multicolumn{3}{|c|}{ Voice Only Disability } & \multicolumn{3}{|c|}{$\begin{array}{l}\text { Speech/Language } \\
\text { Only Disability }\end{array}$} & \multicolumn{3}{|c|}{$\begin{array}{c}\text { Speech/Language and } \\
\text { Voice Disability } \\
\end{array}$} \\
\hline & $\%$ & (n) & $\%$ & (n) & $\mathrm{P}^{*}$ & $\%$ & (n) & $\mathrm{P}^{*}$ & $\%$ & (n) & $\mathrm{P}^{*}$ \\
\hline \multicolumn{12}{|l|}{ Ever diagnosed with } \\
\hline ADD/ADHD & 3.8 & $(940)$ & 4.8 & $(103)$ & $.076^{\ddagger, \|}$ & 14.2 & (89) & $<.001^{\ddagger}$ & 11.7 & $(52)$ & $<.001^{\Perp}$ \\
\hline Bipolar disorder & 1.8 & $(578)$ & 3.5 & (84) & $<.001^{\ddagger, \|}$ & 11.7 & (76) & $<.001^{\ddagger}$ & 11.4 & $(45)$ & $<.001^{\|}$ \\
\hline \multicolumn{12}{|l|}{ In the past 12 months... } \\
\hline \multicolumn{12}{|l|}{ Diagnoses } \\
\hline Phobia/fears & 3.3 & $(986)$ & 7.1 & $(156)$ & $<.001^{\ddagger, \|}$ & 12.8 & $(102)$ & $<.001^{\ddagger}$ & 21.4 & (84) & $<.001^{\|}$ \\
\hline Depression & 8.6 & $(2880)$ & 15.1 & $(381)$ & $<.001^{\ddagger, \|}$ & 30.4 & $(232)$ & $<.001^{\ddagger}$ & 35.9 & (178) & $<.001^{\Perp}$ \\
\hline Other mental health disorders & 2.1 & $(696)$ & 4.3 & $(106)$ & $<.001^{\ddagger, \|}$ & 13.1 & $(107)$ & $<.001^{\ddagger}$ & 15.4 & $(62)$ & $<.001^{\|}$ \\
\hline \multicolumn{12}{|l|}{ Substance use } \\
\hline $\begin{array}{l}\text { Excessive alcohol or tobacco } \\
\text { use }\end{array}$ & 5.5 & $(1714)$ & 7.1 & $(170)$ & $.004^{\ddagger, \|}$ & 15.5 & $(109)$ & $<.001^{\ddagger}$ & 15.7 & $(63)$ & $<.001^{\|}$ \\
\hline Other substance abuse & 0.7 & $(200)$ & 0.7 & $(21)$ & .979 & 1.6 & $(11)$ & .024 & 1.5 & $(8)$ & .075 \\
\hline \multicolumn{12}{|l|}{ Experiences } \\
\hline $\begin{array}{l}\text { Fatigue or lack of energy for } \\
>3 \text { days }\end{array}$ & 13 & $(4010)$ & 31.6 & $(717)$ & $<.001^{\|}$ & 38.7 & (291) & $<.001^{\pi}$ & 54.3 & (264) & $<.001^{\|, \text {, }}$ \\
\hline $\begin{array}{l}\text { Regularly had excessive } \\
\text { sleepiness }\end{array}$ & 10.5 & $(3249)$ & 24 & $(568)$ & $<.001^{\neq, \|}$ & 38.1 & $(282)$ & $<.001^{\neq, \boldsymbol{\pi}}$ & 55.2 & $(255)$ & $<.001^{\| \text {, }, ~}$ \\
\hline $\begin{array}{l}\text { Regularly had insomnia or } \\
\text { trouble sleeping }\end{array}$ & 17 & $(5405)$ & 34.9 & (794) & $<.001^{\|}$ & 42.2 & $(327)$ & $<.001$ & 53.8 & (254) & $<.001 \|$ \\
\hline $\begin{array}{l}\text { Frequently anxious, nervous, or } \\
\text { worried }\end{array}$ & 16.5 & $(5173)$ & 34 & $(765)$ & $<.001^{\ddagger, \|}$ & 51.2 & $(389)$ & $<.001^{\ddagger}$ & 57.4 & $(275)$ & $<.001^{\|}$ \\
\hline Frequently stressed & 26.4 & $(7969)$ & 47.1 & $(1027)$ & $<.001^{\ddagger, \|}$ & 57.5 & $(420)$ & $<.001^{\ddagger}$ & 62.4 & (296) & $<.001^{\Perp}$ \\
\hline $\begin{array}{l}\text { Difficulty participating in social } \\
\text { activities }\end{array}$ & 8.4 & $(2837)$ & 16.2 & $(417)$ & $<.001^{\ddagger, \|}$ & 33.9 & $(280$ & $<.001^{\ddagger, \pi}$ & 47.2 & (231) & $<.001^{\|, \pi}$ \\
\hline \multicolumn{12}{|l|}{ Health care utilization } \\
\hline $\begin{array}{l}\text { Visited mental health } \\
\text { professional }\end{array}$ & 6.8 & $(2133)$ & 11.4 & $(265)$ & $<.001^{\ddagger, \|}$ & 19.1 & $(152)$ & $<.001^{\ddagger}$ & 23.1 & (108) & $<.001^{\|}$ \\
\hline $\begin{array}{l}\text { Could not afford mental } \\
\text { health visit }\end{array}$ & 2 & $(687)$ & 4 & $(90)$ & $<.001^{\ddagger, \|}$ & 11.9 & (76) & $<.001^{\ddagger}$ & 11.7 & $(54)$ & $<.001^{\|}$ \\
\hline \multicolumn{12}{|l|}{ In the past 30 days. . } \\
\hline $\begin{array}{l}\text { Non-specific psychological } \\
\text { distress (K-6) }\end{array}$ & 2.3 & $(787)$ & 4.6 & $(117)$ & $<.001^{\ddagger, \|}$ & 14.7 & (112) & $<.001^{\ddagger}$ & 22.3 & (105) & $<.001^{\|}$ \\
\hline $\begin{array}{l}\text { Feelings interfered with life/ } \\
\text { activities }^{\dagger}\end{array}$ & 11.2 & $(885)$ & 10.7 & (124) & $.716^{\ddagger, \|}$ & 30.2 & (138) & $<.001^{\ddagger}$ & 27.9 & (106) & $<.001^{\|}$ \\
\hline
\end{tabular}

*Statistical significance compares each communication disability group to the group with no communication disabilities.

${ }^{\dagger} \mathrm{n}=9510$; This question was only asked of persons who reported at least one of the items queried in the K6 "all", "most," or "some" of the time.

${ }^{\ddagger}$ Comparison of voice only with speech/language only, $P<.0029$.

"Comparison of voice only with speech/language and voice, $P<.0029$.

${ }^{\pi}$ Comparison of speech/language only with speech/language and voice, $P<.0029$.

$\mathrm{ADD} / \mathrm{ADHD}$, attention deficit disorder/attention deficit hyperactivity disorder.

diagnosed with depression compared with $30.4 \%$ of adults with SL only disabilities $(P<.001)$ and $35.9 \%$ of adults with SLV disabilities $(P<.001)$. Adults with SL only and SLV disabilities more frequently reported other mental illnesses compared with adults without CD (SL only: 13.1\%; SLV: $15.4 \%$; no CD $2.1 \%$; all $P<.001)$. Logistic regression findings were consistent with bivariate results, showing that persons with CDs had 1.6 (1.1 to 2.1) to 3.3 (2.3 to 4.9) times higher odds of reporting mental health diagnoses than their peers without CDs (Figure 1). Persons with SLV disabilities fared worse than their peers with voice only disabilities for phobias (2.1 [1.1 to 3.7]) and other mental health disorders (2.1 [1.0 to 4.1]). Persons with SL only and SLV disabilities had higher likelihoods of depression (SL only: 1.7 [1.1 to 2.6]; 
Figure 1. Forest plot of logistic regression results of behavioral health diagnoses and substance use on communication disabilities, compared with persons without communication disabilities. Abbreviation: ADD/ADHD, attention deficit disorder/attention deficit hyperactivity disorder.

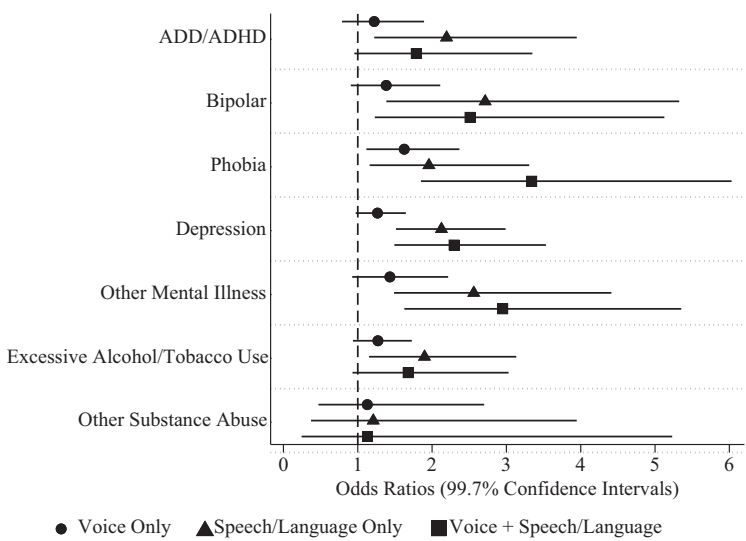

Weighted analyses of adults $(>17)$ who endorsed a voice, speech, and/ or language disability on the 2012 National Health Interview Survey Sample Adult supplement. Logistic regression analyses control for any noncommunication disability, multiple chronic conditions, race/ethnicity, marital status, employment status, educational attainment, imputed poverty status, health insurance, region of residence, sex, and age. CIs that cross the reference line at odds ratio $=1$ are not statistically significant at $P<.0029$.

SLV: 1.8 [1.1 to 2.9$]$ ) than their peers with voice-only disabilities.

Adults with SL only (15.5\%) disabilities reported excessive alcohol and tobacco use nearly 2 times more frequently than their peers without CDs $(5.5 \%$, $P<.001)$. There were no differences in the reporting of other substance use by adults with and without CDs. These findings remained consistent in multivariate analyses.

Adults with CDs also more frequently reported fatigue or lacking energy (voice only: $31.6 \%$; SL only: 38.7\%; SLV: 54.3\%), excessive sleepiness (voice only: $24.0 \%$; SL only: $38.1 \%$; SLV: $55.2 \%$ ), and insomnia or trouble sleeping (voice only: $34.9 \%$, SL only: $42.2 \%$, SLV: $53.8 \%$ ) compared with their peers without CDs (13.0\%, $10.5 \%$, and $17.0 \%$, respectively; all $P<.001)$. Similarly, persons with CDs more frequently endorsed feeling anxious, nervous or worried, and stressed. Adults with voice only disabilities were between 2.1 (1.7-2.6) and 2.3 (1.9-2.9) times more likely than their peers without CDs to have these experiences, as shown in regression analyses (Figure 2). For those same outcomes, the odds for adults with SL only disabilities ranged from 2.1 (1.4-3.0) to 3.1 (2.2 to 4.2) and SLV disabilities ranged from 2.9 (1.84.5 ) to 5.0 (3.1 to 7.9 ) compared with adults without
CDs. Adults with SLV disabilities also fared worse in terms of excessive sleepiness than their peers with voice only (2.4 [1.4-4.0]) and SL only (1.9 [1.1 to 3.3]) disabilities.

Approximately $16 \%$ of adults with voice only, $34 \%$ of adults with SL only, and $47 \%$ of adults with SLV disabilities reported difficulty participating in social activities, compared with $8.5 \%$ of adults without CDs (all $P<.001$ ). These differences remained statistically significant in multivariate analyses. For example, persons with SLV disabilities were 2.7 (1.8-4.2) times more likely to report difficulty participating than their peers without disabilities. Persons with SLV disabilities were also more likely to report difficulties than their peers with voice only disabilities (2.0 [1.2 to 3.3]).

Adults with CDs also more frequently reported nonspecific psychological distress in the past 30 days (SL only: 14.7\%; SLV: 22.3\%) compared with adults without CDs $(2.3 \% ; P<.001)$. Persons with SL disabilities more frequently reported that those feelings interfered with their lives and activities (SL only: 30.2\%) compared with adults without CDs $(11.2 \% ; P<.001)$. Logistic regression models were consistent with the bivariate results, which show persons with CDs had 2.1 (1.6-2.9) to 4.0 (2.5 to 6.6) higher odds of reporting nonspecific psychological

Figure 2. Forest plot of logistic regression results of behavioral health experiences on communication disabilities, compared with persons without communication disabilities. Abbreviation: NSPD, Nonspecific Psychological Distress.

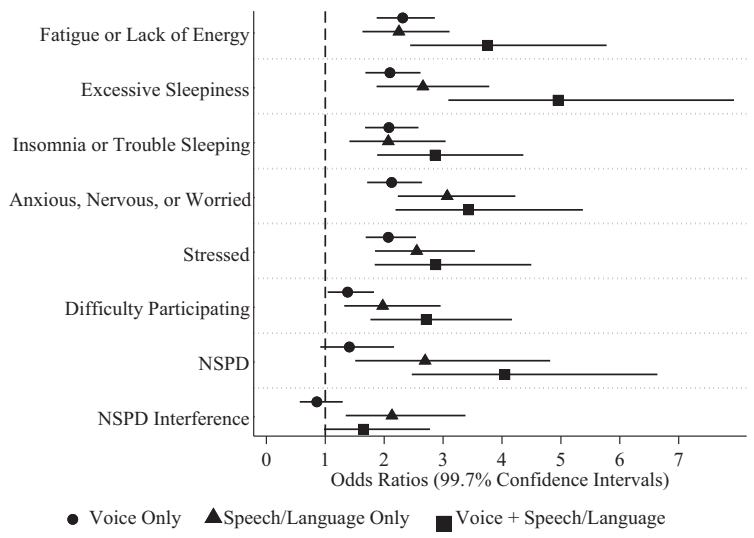

Weighted analyses of adults (>17) who endorsed a voice, speech, and/or languag disability on the 2012 National Health Interview Survey Sample Adult supplement. Logistic regression analyses control for any noncommunication disability, multiple chronic conditions, race/ethnicity, marital status, employment status, educational attainment, imputed poverty status, health insurance, region of residence, sex, and age. CIs that cross the reference line at odds ratio $=1$ are not statistically significant at $P<.0029$. 
distress than their peers. Persons with SLV disabilities fared worse than their peers with voice only disabilities (2.9 [1.6-5.2]). Persons with SL only and SLV disabilities were more likely than their peers with voice only disabilities to report that their distress interfered with their lives (SL only: 2.5 [1.4-4.5]; SLV: 1.9 [1.0 to 3.7]).

Adults with CDs more frequently endorsed visiting a mental health professional (voice only: $11.4 \%$, SL only: $19.1 \%$, SLV: 23.1\%) compared with adults without CDs $(6.8 \%$, all $P<.001)$, but these differences became nonsignificant in multivariate analyses that controlled for behavioral health diagnoses and experiences (results not shown). With the exception of persons with SL only disabilities, bivariate statistically significant differences for CD and foregoing mental health care due to cost became nonsignificant in multivariate analyses, controlling for behavioral health conditions. Approximately $12 \%$ of persons with SL only disabilities reported foregoing care due to cost compared with $2.0 \%$ of adults without CDs $(P<.001)$. Multivariate analyses remained statistically significant for this group, revealing that persons with SLonly disabilities were 2.0 (1.1 to 3.7$)$ times more likely to forego care because of cost than their peers without CDs (results not shown).

\section{Sensitivity Analyses}

In 2018, the NHIS added 1 permanent question regarding CDs to the Sample Adult survey. The question asks respondents to rate their level of "difficulty communicating, for example, understanding or being understood" in their "usual language." It does not differentiate between types of CD. From 2011 to 2017 , this question was asked of only half of the sample adults who participated in the Adult Functioning and Disability Questionnaire. We reran our analyses on the behavioral health measures available in the 2018 NHIS: feeling anxious, nervous, or worry; nonspecific psychological distress; visits to a mental health professional; and unmet need for mental health care due to cost. These findings were consistent with the 2012 findings for persons with any SL disability.

\section{Discussion}

In this population level analysis of behavioral health outcomes in adults with voice, speech, and language disabilities, we found that adults with CDs have poorer behavioral health outcomes than their peers without CDs. Our sample included heterogeneous disease etiologies, revealing the commonality of experience among adults with CDs. Adults with CDs were 1.6-3.3 times as likely to have a mental health diagnosis, 2.0 times more likely to have excessive alcohol and tobacco use, and 2.1 to 5.0 times more likely to have stress-related experiences compared with adults without CDs. These findings align with prior, smaller scale studies of clinical samples with single CD etiologies ${ }^{11,12,15-17}$ and among persons with hearing loss and deafness. ${ }^{23-25} \mathrm{We}$ also found that, despite poorer behavioral health, adults with CDs are no more likely than their peers to visit mental health professionals.

The relationship between experiencing a $\mathrm{CD}$ and poor behavioral health is likely complex and multifactorial. In our sample, persons with CDs had fewer socioeconomic resources available to them as compared with those without CDs. This is consistent with prior literature, which acknowledges the influential role of social determinants on the health outcomes of persons with disabilities. ${ }^{26-28}$ However, we also found that the relationship of experiencing a $\mathrm{CD}$ and behavioral health outcomes remained even after adjusting for these factors. One potential explanation is the social isolation that can occur as a result of having a CD. All CD groups endorsed difficulties participating in social activities at higher rates than their nondisabled peers. In addition, the CD subgroup with the highest rates of social participation restrictions, persons with SLV disabilities, also had the poorest behavioral health outcomes. This suggests that social participation limitations play an important role in the relationship between experiencing a CD and behavioral health. This relationship also aligns with findings previously reported in the literature. ${ }^{3,4,29}$ When comparing CD subgroups, persons with SL disorders fared worse than those with voice only disorders on many behavioral health outcomes. One final potential explanation for this is related to the high rate of neurologic etiologies that result in SL disabilities, such as traumatic brain injuries and strokes. This damage could result in neurological changes that lead to behavioral health outcomes. ${ }^{30,31}$

We found that despite consistently poorer behavioral health outcomes experienced by persons with CDs, behavioral health services were underutilized. There are several possible reasons for this. The first is the problem of cost, as respondents 
with CDs more frequently reported being unable to afford mental health services. All 3 CD groups had higher rates of unemployment and being on public insurance than did persons without CDs. Notably, underutilization of behavioral health care contrasts the pattern of higher physical medicine utilization rates of office-based visits, emergency department visits, and inpatient hospital stays found in this same NHIS sample in Stransky et al. ${ }^{2}$ It is conceivable that this is also related to cost. When forced to choose between competing health care needs in this resource constrained population, acute physical needs may take precedence over behavioral ones.

The paucity of mental health identification and assessment methods validated on persons with CD could lead to under-identification of behavioral health disorders in this population. ${ }^{32,33}$ Qualitative evidence from primary care indicates that persons with CDs interact with and convey messages to their physicians differently than those without CDs. ${ }^{34-36}$ Persons with CDs rely heavily on caregivers for communication, need additional time to be understood, and are at risk of feeling misunderstood by their health care practitioners. ${ }^{34}$ Even the most seasoned clinicians endorse challenges in identifying the emotional state of persons with CDs. ${ }^{37}$ Validated identification and assessment methods for this group are needed to ensure behavioral health symptoms are not missed or inappropriately treated.

There are also few psychological and pharmacological treatment approaches specifically validated on persons with CDs. ${ }^{26,38-46}$ The mainstay of psychological services is psychotherapy, also known as "talk therapy," 47 which poses inherent challenges for those with CDs. Fortunately, approaches are emerging in the aphasia population, with several new behavioral health approaches under investigation. ${ }^{32,44,48-50}$ Another opportunity for addressing these needs is the addition of speech-language pathologists as part of the primary care and behavioral health team. ${ }^{51}$ Such providers are specifically trained in addressing CDs and can work with both the patient and providers to improve communication and understanding of symptoms and treatment effects.

\section{Limitations}

The conclusions drawn from this study are limited by the cross-sectional nature of the design. As this is an exploratory study, it is not meant to provide causal explanations, but rather to describe the experience of this population. A second limitation is the age of the data, as the 2012 NHIS was the only year that multiple questions were asked distinguishing specific types of CD experienced by respondents. The 2012 NHIS specification by type of CD allowed for stratification of CD groups not possible in any other year. This was important given the notable differences in the duration of experiencing their CD and behavioral health prevalence rates in adults with voice as compared with adults with SL and SLV CDs.

\section{Conclusion}

Persons with CDs are at high risk for poor behavioral health and health care outcomes. Future studies should continue to investigate the underlying drivers of this phenomenon. The development of behavioral health screening tools and interventions validated on this patient population is essential. Finally, national data collection efforts on disability should consistently include CDs, differentiating among persons with voice, speech, and language CDs. Only then can we hope to improve the state of behavioral health and health care in this population. After all, persons with CDs deserve an equal opportunity to achieve not just optimal physical health, but also the highest behavioral health possible.

To see this article online, please go to: http://jabfm.org/content/ 33/6/932.full.

\section{References}

1. Bartlett G, Blais R, Tamblyn R, Clermont RJ, MacGibbon B. Impact of patient communication problems on the risk of preventable adverse events in acute care settings. Can Med Assoc J 2008;178:1555-62.

2. Stransky ML, Jensen KM, Morris MA. Adults with communication disabilities experience poorer health and healthcare outcomes compared to persons without communication disabilities. J Gen Intern Med 2018;33:2147-55.

3. Palmer AD, Newsom JT, Rook KS. How does difficulty communicating affect the social relationships of older adults? An exploration using data from a national survey. J Commun Disord 2016;62:131-46.

4. Palmer AD, Carder PC, White DL, et al. The impact of communication impairments on the social relationships of older adults: pathways to psychological wellbeing. J Speech Lang Hear Res 2019;62:1-21. 
5. Morris MA, Meier SK, Griffin JM, Branda ME, Phelan SM. Prevalence and etiologies of adult communication disabilities in the United States: results from the 2012 National Health Interview Survey. Disabil Health J 2016;9:140-4.

6. Houtenville A, Boege S. Annual report on people with disabilities in America: 2018. Durham, NH: University of New Hampshire, Institute on Disability/UCED; 2019.

7. Peek CJ. Lexicon for behavioral health and primary care integration. Rockville, MD: Agency for Healthcare Research and Quality; 2013.

8. Mental health: Overview and Impact. U.S. Department of Health and Human Services. Available from: https://www.healthypeople.gov/ 2020/leading-health-indicators/2020-lhi-topics/ Mental-Health. Accessed January 26, 2020.

9. McAuliffe MJ, Schluter PJ, Jamieson HA. An epidemiological profile of communication disability among older adults with complex needs: a national cross-sectional study. Int J Speech Lang Pathol 2019;21:537-46.

10. Baylor C, Burns M, Eadie T, Britton D, Yorkston K. A qualitative study of interference with communicative participation across communication disorders in adults. Am J Speech Lang Pathol 2011;20:269-87.

11. Bussian C, Wollbrück D, Danker H, et al. Mental health after laryngectomy and partial laryngectomy: a comparative study. Eur Arch Otorhinolaryngol 2010;267:261-6.

12. Dietrich M, Verdolini Abbott K, Gartner-Schmidt J, Rosen CA. The frequency of perceived stress, anxiety, and depression in patients with common pathologies affecting voice. J Voice 2008;22:472-88.

13. Misono S, Peterson CB, Meredith L, et al. Psychosocial distress in patients presenting with voice concerns. J Voice 2014;28:753-61.

14. Substance Abuse and Mental Health Services Administration. Key substance use and mental health indicators in the United States: results from the 2017 National Survey on Drug Use and Health. Rockville, MD: HHS Publication No. SMA 185068, NSDUH Series H-53; 2018.

15. Ardila A, Bateman J, Niño CR, Pulido E, Rivera DB, Vanegas CJ. An epidemiologic study of stuttering. J Commun Disord 1994;27:37-48.

16. Aström M, Adolfsson R, Asplund K. Major depression in stroke patients. A 3-year longitudinal study. Stroke 1993;24:976-82.

17. Mitchell AJ, Sheth B, Gill J, et al. Prevalence and predictors of post-stroke mood disorders: a metaanalysis and meta-regression of depression, anxiety and adjustment disorder. Gen Hosp Psychiatry 2017;47:48-60.

18. Healthy People 2020. Washington, DC: Department of Health and Human Services, Office of Disease Prevention and Health Promotion; 2020.
19. National Center for Health Statistics. National Health Interview Survey 2012, data file. Hyattsville, MD: Centers for Disease Control and Prevention; 2012.

20. Kessler RC, Demler O, Frank RG, et al. Prevalence and treatment of mental disorders, 1990 to 2003. N Engl J Med 2005;352:2515-23.

21. Stata Statistical Software: Release 15. [computer program]. College Station, TX: StataCorp LLC; 2017.

22. Bender R, Lange $\mathrm{S}$. Adjusting for multiple testingWhen and how?. J Clin Epidemiol 2001;54:343-9.

23. Mick P, Kawachi I, Lin FR. The association between hearing loss and social isolation in older adults. Otolaryngol Head Neck Surg 2014;150:378-84.

24. Lin FR. Hearing loss in older adults. JAMA 2012;307:1147-8.

25. Weinstein BE, Ventry IM. Hearing impairment and social isolation in the elderly. J Speech Hear Res 1982;25:593-9.

26. Krahn G, Campbell VA. Evolving views of disability and public health: the roles of advocacy and public health. Disabil Health J 2011;4:12-8.

27. Frier A, Barnett F, Devine S, Barker R. Understanding disability and the 'social determinants of health': how does disability affect peoples' social determinants of health? Disabil Rehabil 2018;40:538-47.

28. Cieza A, Sabariego C, Bickenbach J, Chatterji S. Rethinking disability. BMC Med 2018;16:14.

29. Ford A, Douglas J, O'Halloran R. The experience of close personal relationships from the perspective of people with aphasia: thematic analysis of the literature. Aphasiology 2018;32:367-93.

30. National Institute on Deafness and Other Communication Disorders. Statistics on Voice, Speech, and Language. 2016. Available from: https:// www.nidcd.nih.gov/health/statistics/statistics-voicespeech-and-language. Accessed March 23, 2020.

31. Fann JR, Hart T, Schomer KG. Treatment for depression after traumatic brain injury: a systematic review. J Neurotrauma 2009;26:2383-402.

32. Baker C, Worrall L, Rose M, Ryan B. Experiences of mood changes and depression after post-stroke aphasia. Aphasiology 2018;32:11-2.

33. Laures-Gore JS, Farina M, Moore E, Russell S. Stress and depression scales in aphasia: relation between the aphasia depression rating scale, Stroke Aphasia Depression Questionnaire-10, and the perceived stress scale. Topics Stroke Rehabil 2017;24: 114-8.

34. Morris MA, Dudgeon BJ, Yorkston K. A qualitative study of adult AAC users' experiences communicating with medical providers. Disabil Rehabil Assist Technol 2013;8:472-81.

35. Morris MA, Clayman ML, Peters KJ, Leppin AL, LeBlanc A. Patient-centered communication 
strategies for patients with aphasia: discrepancies between what patients want and what physicians do. Disabil Health J 2015;8:208-15.

36. Burns M, Baylor C, Dudgeon BJ, Starks H, Yorkston K. Asking the stakeholders: perspectives of individuals with aphasia, their family members, and physicians regarding communication in medical interactions. Am J Speech Lang Pathol 2015;24:341-57.

37. Bullain SS, Chriki LS, Stern TA. Aphasia: associated disturbances in affect, behavior, and cognition in the setting of speech and language difficulties. Psychosomatics 2007;48:258-64.

38. Ryan B, Bohan J, Kneebone I. Help-seeking and people with aphasia who have mood problems after stroke: perspectives of speech-language pathologists. Int J Lang Commun Disord 2019;54:779-93.

39. Ryan B, Hudson K, Worrall L, et al. The aphasia action, success, and knowledge programme: results from an Australian phase I trial of a speech-pathology-led intervention for people with aphasia early post stroke. Brain Impairment 2017;18:284-98.

40. Kneebone II, Dunmore E. Psychological management of post-stroke depression. Br J Clin Psychol 2000;39:53-65.

41. Kneebone II, Lincoln NB. Psychological problems after stroke and their management: state of knowledge. Neuroscience and Medicine 2012;3:83.

42. Townend E, Brady M, McLaughlan K. A systematic evaluation of the adaptation of depression diagnostic methods for stroke survivors who have aphasia. Stroke 2007;38:3076-83.

43. Willner P. The effectiveness of psychotherapeutic interventions for people with learning disabilities: a critical overview. J Intellect Disabil Res 2005;49: 73-85.
44. Santo Pietro MJ, Marks DR, Mullen A. When words fail: providing effective psychological treatment for depression in persons with aphasia. J Clin Psychol Med Settings 2019;26:483-94.

45. Kehayia E, Korner-Bitensky N, Singer F, et al. Differences in pain medication use in stroke patients with aphasia and without aphasia. Stroke 1997;28:1867-70.

46. Chandrasekhar T, Sikich L. Challenges in the diagnosis and treatment of depression in autism spectrum disorders across the lifespan. Dialogues Clin Neurosci 2015;17:219-27.

47. The National Institute of Mental Health. Psychotherapies. 2016. Available from: https://www. nimh.nih.gov/health/topics/psychotherapies/index. shtml. Accessed November 27, 2019.

48. Thomas SA, Walker MF, Macniven JA, Haworth $\mathrm{H}$, Lincoln NB. Communication and low mood (CALM): a randomized controlled trial of behavioural therapy for stroke patients with aphasia. Clin Rehabil 2013;27:398-408.

49. Hilari K, Behn N, Marshall J, et al. Supporting wellbeing through peer-befriending (SUPERB) trial: an exploration of fidelity in peer-befriending for people with aphasia. Brain Injury 2019;33:303-4.

50. Northcott S, Simpson A, Thomas S, Hirani SP, Flood C, Hilari K. Solution focused brief therapy in post-stroke aphasia (SOFIA Trial): protocol for a feasibility randomised controlled trial. AMRC Open Res 2019;1:11.

51. Sekhon JK, Oates J, Kneebone I, Rose M. Counselling training for speech-language therapists working with people affected by post-stroke aphasia: a systematic review. Int J Lang Commun Disord 2019;54:321-46. 